\title{
Microstructural Adjustments and Tensile Properties of a Hot-Forged Ti-22Al-23Nb-3V-Y Alloy
}

\author{
Hairui Zhang ${ }^{\circledR}$, Hongzhi Niu $^{a *}$, Qianqian Sun ${ }^{a}$, Deliang Zhang ${ }^{a}$ \\ anstitute of Ceramics and Powder Metallurgy, School of Materials Science and Engineering, \\ Northeastern University, Shenyang 110819, China
}

Received: November 22, 2018; Revised: February 16, 2019; Accepted: April 29, 2019

\begin{abstract}
Microstructures and tensile properties of a hot forged $\mathrm{Ti}-22 \mathrm{Al}-23 \mathrm{Nb}-3 \mathrm{~V}-\mathrm{Y}$ alloy were investigated systematically. Different heat treatments were performed to adjust the wrought microstructure to optimize tensile properties. It was found that features of $\mathrm{O}$ phase precipitates and its volume fraction was rather sensitive to the cooling rate after the solution. The volume fraction of primary lamellar O phase increased from $19.65 \%$ by solution treatment to $36.30 \%$ by annealing with furnace cooling and up to $100 \%$ by annealing with a controlled slow cooling rate of $1{ }^{\circ} \mathrm{C} / \mathrm{min}$. Meanwhile, the width of the lamellar secondary $\mathrm{O}$ phase increased. Fine acicular second $\mathrm{O}$ phase contributed to strengthening, while the coarsen primary ones were favorable to the ductility. The solution \& aging treated microstructure exhibited a good tensile strength of $1100 \mathrm{MPa}$ and an acceptable ductility of $8 \%$ at room temperature, by contrast, annealing at $950{ }^{\circ} \mathrm{C}$ with a controlled slow cooling rate gave rise to a higher elongation of $12 \%$, but a relatively low strength of $960 \mathrm{MPa}$.
\end{abstract}

Keywords: Ti AlNb alloy, Forging, Heat treatments, Microstructures, Mechanical properties.

\section{Introduction}

$\mathrm{Ti}_{2} \mathrm{AlNb}$ based alloys are important intermetallics serving as high-temperature structural materials ${ }^{1}$, because of their excellent strength-to-weight ratio, improved oxidation resistance and good creep resistance properties $^{2-5}$. They are being considered as ideal light-weight alloys to replace Ni-based alloys at service temperatures up to $700{ }^{\circ} \mathrm{C}$, in order to improve the performance of aero-engines ${ }^{6}$.

Phases of $\mathrm{Ti}_{2} \mathrm{AlNb}$ alloys include orthorhombic $\mathrm{O}$, hexagonal intermetallic $\alpha_{2}$ and B2 $2^{7,8}$. Studies have shown that deformation or creep resistance originated from the $\alpha_{2}$ phase with the hcp structure and the $\mathrm{O}$ phase with an ordered orthorhombic structure based on $\mathrm{Ti}_{2} \mathrm{AlNb}$, the lamellar $\mathrm{O}$ have better creep resistance than B2 ${ }^{9}$. The plasticity of the alloy stems from the B2 with more slip systems. The precipitation of $\alpha_{2}$ phase at low temperature is very slow, the twin deformation is restrained due to the order in a long-range. Generally, $\alpha_{2}$ phase is a brittle phase in TiAl intermetallics because it has few independent sliding systems. S.R. Dey reported that the further addition of $\mathrm{Nb}$ (beyond 11at\%) stabilized the ordered orthorhombic $\mathrm{O}$ phase, an addition of $\mathrm{Nb}$ beyond $23 \%$ further stabilized the two phase $\mathrm{O}+\mathrm{B} 2$ region in the high temperature range ${ }^{10}$, which exhibited better mechanical properties than that of $\alpha_{2}+$ B2 alloys.

To get superior mechanical properties, one way is elements adjustment, another is heat treatment. Alloys with relatively high niobium contents (17-27 at \%) containing primarily $\mathrm{O}$ phase rather than $\alpha_{2}$ possess relatively higher combinations of strength, toughness and creep resistance properties ${ }^{11}$.

*e-mail: niuhongzhi@mail.neu.edu.cn
But niobium is prone to segregating during casting, substituting Mo, $\mathrm{V}$ for $\mathrm{Nb}$, Feng Tang developed the Ti-22Al-24Nb-2V and Ti-22Al-11 Nb-4Mo, through $1050^{\circ} \mathrm{C} / 1 \mathrm{~h} / \mathrm{CC}$ (controlled cooling rate at $3{ }^{\circ} \mathrm{C} / \mathrm{min}$ ) $+850{ }^{\circ} \mathrm{C} / 33 \mathrm{~h} / \mathrm{WQ}$ (water quench), the colony size of $\mathrm{Ti}-22 \mathrm{Al}-24 \mathrm{Nb}-2 \mathrm{~V}$ was $148 \mu \mathrm{m}$, consisted of $\mathrm{B} 2+\mathrm{O}, 32 \%$ of which were $\mathrm{B} 2$; the colony size of Ti-22Al$11 \mathrm{Nb}-4 \mathrm{Mo}$ was $252 \mu \mathrm{m}$, consisted of $\mathrm{B} 2+\alpha_{2}, 55 \%$ of which were B2. The creep rate of Ti-22Al-24Nb-2V was more lower, but both Young's Modulus and Vickers hardness at Room Temperature increased ${ }^{12}$. For the Ti-22Al-26Nb alloy, the addition of $5 \mathrm{at} \%$ boron proved to be detrimental to the tensile and creep behaviour ${ }^{13,14}$. The substitution of $2 \% \mathrm{~W}$ for $7 \%$ $\mathrm{Nb}$ in Ti-22Al-27Nb was quite effective in increasing tensile strength at temperatures above $923 \mathrm{~K}$ and in reducing the steady state creep rate and primary creep strain ${ }^{12,15}$. The microstructure was sensitive to the cooling rate, through $1130^{\circ} \mathrm{C} / 1 \mathrm{~h} / \mathrm{CC}\left(3^{\circ} \mathrm{C} /\right.$ $\min$ and $\left.30^{\circ} \mathrm{C} / \mathrm{min}\right)+850^{\circ} \mathrm{C} / 33 \mathrm{~h} / \mathrm{WQ}$, the structure of Ti-22Al$20 \mathrm{Nb}-2 \mathrm{~W}$ consisted of $\mathrm{B} 2+\mathrm{O}$, while reducing the cooling rate to $0.3{ }^{\circ} \mathrm{C} / \mathrm{min}$, phase compositions were $\mathrm{B} 2+\mathrm{O}+\alpha_{2}, 19 \%$ of which was $\alpha_{2}{ }^{12}$. Small rod-shaped primary $\alpha_{2}$ phase deformed slightly in the $\alpha_{2}+$ B2 two-phase region led to poor long-term high temperature properties in addition to the poor ductility ${ }^{16}$. Hence, through appropriate heat treatment to reduce the $\alpha_{2}$ phase and the phase boundary, the elongation can be increased by 2.5 times ${ }^{17}$. For the B2+O alloys, cracks were also easily nucleated at the equiaxed $\mathrm{O} / \mathrm{O}$ boundaries, resulting in intergranular fractures, while the $\mathrm{B} 2$ phase has the crack passivation ability and dimple characteristics along the waveform slip, leading to a combination of optimized strength and toughness. When the volume fraction of B2 phase is more than $15 \%$, the stress concentration effect at the interface can be reduced. 
Otherwise, the crack easily initiates from the $\mathrm{O} / \mathrm{O}$ grain boundary at the low strain level ${ }^{1}$. The coarse-lath $\mathrm{O}$ has better creep resistance than fine $\mathrm{O}^{18}$. Therefore, it is also critical to control the cooling rate of heat treatment.

Yang ${ }^{19}$ reported that the size of the sheet $\mathrm{O}$ phase was determined by the aging temperature and cooling rate. $\mathrm{CaO}^{20}$ studied $\alpha_{2}+\mathrm{B} 2+\mathrm{O}$ three-phase alloys and it was believed that the presence of anomalous long-plate $O$ phase in the microstructure and the larger size of $\beta$ grains also reduced the ductility of the alloy. Zeng ${ }^{21}$ discovered that after solution treatment and aging process, both phases(the coarsened lamellar $\mathrm{O}$ phase and the fine acicular $\mathrm{O}$ phase) existed in the microstructure of the Ti-22Al-25Nb alloy, the ductility increased with the thickness of the lamellar O phase increasing in single distribution region (opposite to bimodal region). Ductility in bimodal distribution region was higher than the single distribution because of the decrease of $\alpha_{2}$ particles.

Zheng got the billet with the isothermally compressing in the $\mathrm{B} 2$ phase, then air cooling to room temperature and after $960{ }^{\circ} \mathrm{C} / 1 \mathrm{~h} / \mathrm{WC}$ (water cooling) $+780{ }^{\circ} \mathrm{C} / 12 \mathrm{~h} / \mathrm{AC}$ (air cooling), it was concluded that the microstructure with a high-volume fraction of $\mathrm{O}$ phase got higher strength and lower elongation, but refined B2 grains exerted a good mechanical property. Forging with a higher volume fraction of B2 and finer B2, more B2 was observed at grain boundaries and reported high fracture toughness ${ }^{22}$.

The size and volume fraction of secondary acicular $\mathrm{O}$ can affect the mechanical properties strongly ${ }^{13}$. The coarse lamellar $\mathrm{O}$ precipitations during solution process improved the ductility, while the fine lamellar O precipitated during aging process and strengthened the alloy ${ }^{21}$. The mechanical properties of Ti2AlNb alloy mainly depended on grain size of prior B2 phase grains and the lamellar thickness of $\mathrm{O}$ phase precipitates ${ }^{23}$. Generally, proper coarsening of $O$ phase precipitates resulted in high tensile elongation to fracture, while fine acicular O phase contributed to strengthening ${ }^{24}$.

The mechanical propertity of $\mathrm{Ti}_{2} \mathrm{AlNb}$ alloys depend on the microstructure of the alloy, whereas the phase equilibrium and microstructure evolutions are very complex. Under different thermal processing techniques, $\mathrm{Ti}_{2} \mathrm{AlNb}$ alloys have single-phase, two-phase, or three-phase structures. In addition, the size, volume fraction, and morphology of these phases also have a large influence on mechanical properties. Therefore, there is an urgent need to further explore the relationship between the microstructure and mechanical properties. In this study, by means of heat treatments on a wrought $\mathrm{Ti}-22 \mathrm{Al}-23 \mathrm{Nb}-3 \mathrm{~V}-\mathrm{Y}$ alloy (at \%), the effect of sizes and volume fractions of the $\mathrm{O}-\mathrm{Ti}_{2} \mathrm{AlNb}$ phase precipitates on mechanical properties was investigated systematically.

\section{Materials and Experimental Procedure}

A Ti-22Al-23Nb-3V-Y alloy (at \%) ingot with dimensions of $\Phi 160 \times 300 \mathrm{~mm}^{3}$ was produced by three times vacuum arc remelting process. The actual chemical composition was measured to be $\mathrm{Ti}-21.8 \mathrm{Al}-23.2 \mathrm{Nb}-2.8 \mathrm{~V}-0.9 \mathrm{Y}$ by Inductive Coupled Plasma emission spectrometry method (ICP). The ingot was machined into a billet of $150 \mathrm{~mm}$ in diameter and $220 \mathrm{~mm}$ in length and then was canned by 304 steel. A hot forging process was conducted on this billet at $1150{ }^{\circ} \mathrm{C}$ and $0.05 \mathrm{~s}^{-1}$ with a reduction of $80 \%$.

Microstructures were characterized by optical microscopy (OM), scanning electron microscopy (SEM) and transmission electron microscopy (TEM) techniques. Optical micrographs were observed using a Zeiss microscope. For high-magnification microstructure observations, field emission SEM (JSM-6700) and a $200 \mathrm{kV}$ TEM (JEOL JEM-200CX) were adopted. Volume and microstructural characteristics of $\mathrm{O}$ phase were measured using the software Image Pro Plus. TEM foils were prepared by standard mechanical polishing and twin-jet electropolishing using a solution of $6 \%$ perchloric acid $+34 \%$ butanol $+60 \%$ methanol at $-20{ }^{\circ} \mathrm{C}$ and $25 \mathrm{~V}$.

In order to adjust microstructures of the wrought alloy, solution and aging treatments were conducted on $\Phi 8 \mathrm{~mm} \times 5 \mathrm{~mm}$ samples in a program-controlled muffle furnace. Through DSC test, the transformation temperature from the $\mathrm{B} 2+\mathrm{O}+\alpha_{2}$ to $\mathrm{B} 2+\alpha_{2}$ was $1020{ }^{\circ} \mathrm{C}$, the solution temperature was 1000 ${ }^{\circ} \mathrm{C}$, which was in the $\mathrm{B} 2+\mathrm{O}$ region. Tensile tests of dog-bone shaped specimens, having a rectangular cross section of 2 $\mathrm{mmX} 2 \mathrm{~mm}$ and gauge length of $20 \mathrm{~mm}$, and cut from the center were performed on an Instron 5500R machine at a crosshead speed of $0.5 \mathrm{~mm} / \mathrm{min}$ at room temperature and $700{ }^{\circ} \mathrm{C}$.

\section{Results and Discussion}

\subsection{Microstructural characteristics of the casting ingot}

Fig. 1((a) and (b)) present the casting ingot microstructures of the Ti-22Al-23Nb-3V-Y alloy. The microstructure was Widmanstatten with the grain size of about $200 \mu \mathrm{m}$ and refined grains were observed because of an addition of rare earth element Y. The OM image (Fig. 1 (a)) shows some macroscopic segregations in the as-cast microstructure, the white regions were $\mathrm{Nb}$ segregations and the black dots were Al segregations. The SEM image (Fig. 1(b)) shows the white parts were $\mathrm{B} 2$ phase and the black parts were $\mathrm{O}$ phase. Acicular $\mathrm{O}$ phase precipitated at the grain boundaries and in the B2 matrix unevenly, there were more $\mathrm{O}$ phases at the grain boundary. Consequently, we need to improve the microstructure through the thermal mechanical deformation. 


\subsection{Microstructural characteristics of the wrought alloy}

Fig. 2((a) and (b)) present the microstructures of the wrought alloy. The OM image (Fig. 2(a)) shows the significant streamline after deformation along the forging direction. The microstructure presented serrated B2 grain boundaries, which were stretched and refined ranging from $10 \mu \mathrm{m}$ to $150 \mu \mathrm{m}$, the mean size of about $60 \mu \mathrm{m}$ was much less than the size of forging in the B2 region of $950 \mu \mathrm{m}^{22}$. Some small triangular grains existing at the $\mathrm{B} 2$ boundaries and appearance of black dots $\left(\mathrm{Y}_{2} \mathrm{O}_{3}\right)$, as shown in Fig (2(a)), may suggest the occurrence of the recrysrallization. The SEM image (Fig. 2(b)) shows that more and more needle shape $\mathrm{O}$ phase precipitated in the B2 matrix and at the grain boundaries in the process of air cooling to the room temperature. Comparing with the microstructure of the casting, consecutive $\mathrm{O}$ phase appeared in the B2 matrix, because more distortion energy was accumulated in the crystal, which facilitated the nucleation of the $\mathrm{O}$ phase.
Furthermore, the cooling rate was fast, the $\mathrm{O}$ phase was too late to grow up, the number of $\mathrm{O}$ phase increased significantly, meanwhile, the length was shortened, which was approximately the short-rod, $\alpha_{2}$ phase was not observed in the microstructure.

\subsection{Microstructural adjustments of the wrought alloy}

Fig. 3((a)-(d)) display phase constitutions of the different heat treatment conditions. Fig. 3(a) and (b) represent the solution treatment at $1000{ }^{\circ} \mathrm{C} / 1 \mathrm{~h} / \mathrm{WQ}$ and aging treatment at $820^{\circ} \mathrm{C} / 8 \mathrm{~h} / \mathrm{FC}(\mathrm{STA})$, there were two size levels of the $\mathrm{O}$ laths. The primary lenticular $\mathrm{O}$ phase precipitated prior at the grain boundaries and the second acicular $\mathrm{O}$ phase precipitated in the B2 grain. The mean length and width of the primary $\mathrm{O}$ is about $2.58 \mu \mathrm{m}$ and $0.67 \mu \mathrm{m}$, respectively, while the mean length and width of the second $\mathrm{O}$ is about $0.42 \mu \mathrm{m}$ and $75 \mathrm{~nm}$, respectively, as shown in Fig. 3(a) and Tab 1. After the annealing at $1000{ }^{\circ} \mathrm{C} 1 \mathrm{~h} / \mathrm{FC}$ (furnace cooling), the elements diffused sufficiently, so that both the primary

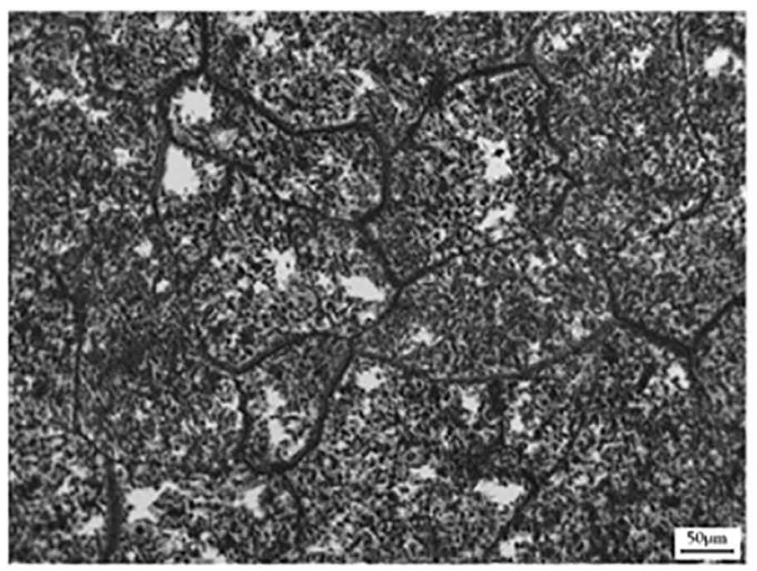

(a) OM image

Figure 1. Microstructures of Ti-22Al-24Nb-3V-Y cast ingot

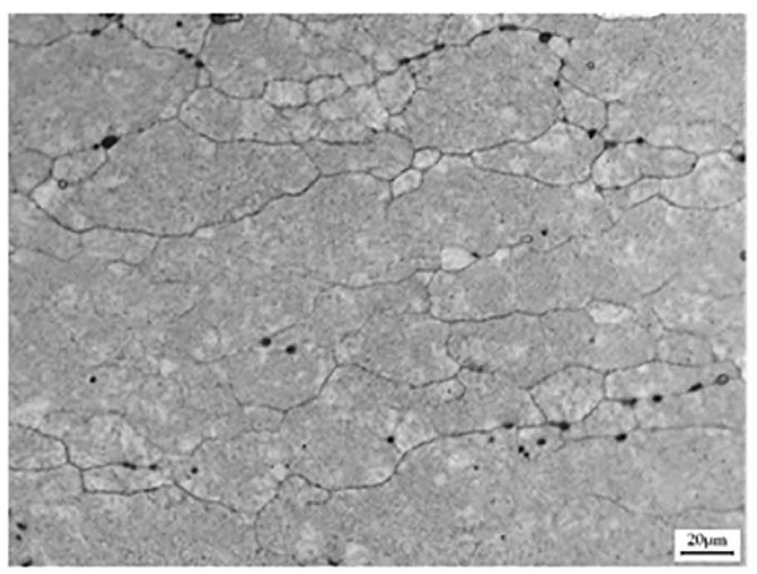

(a) OM image

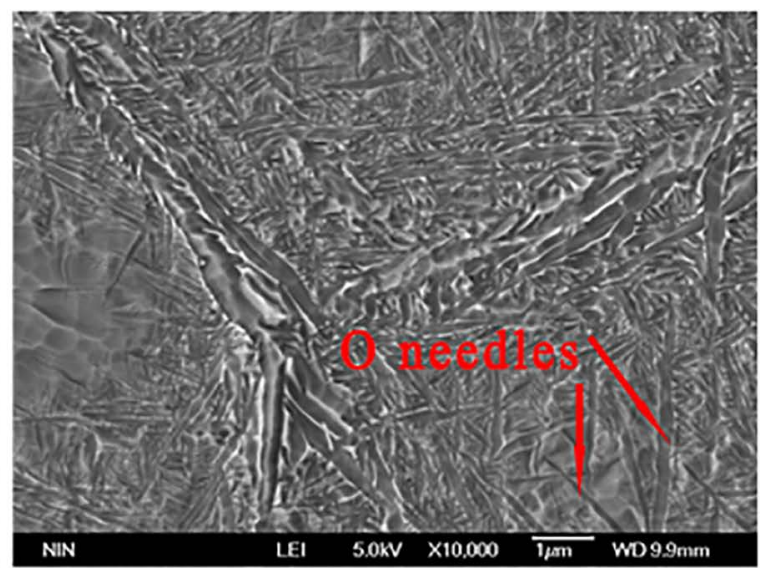

(b) SEM image

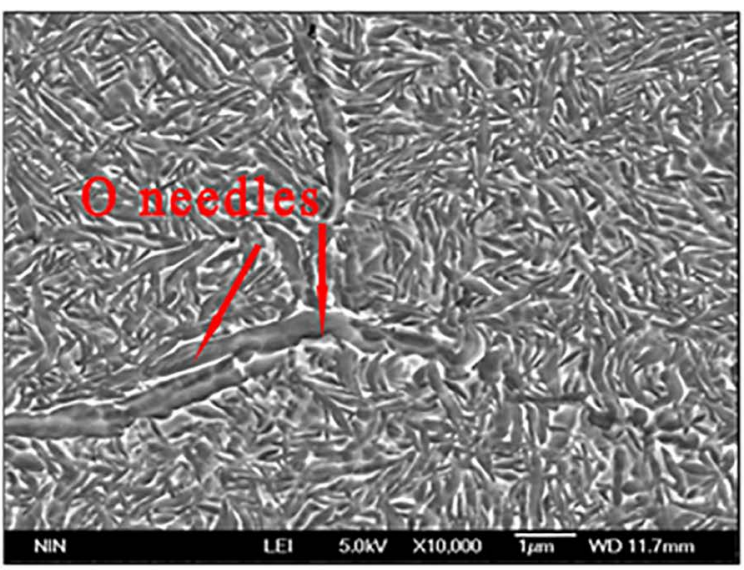

(b) SEM image

Figure 2. As-forged microstructures of the present $\mathrm{Ti}_{2} \mathrm{AlNb}$ alloy. 
$\mathrm{O}$ phase and the secondary $\mathrm{O}$ phase grew significantly. The width and the length of the primary $\mathrm{O}$ phase increased to $0.98 \mu \mathrm{m}$ and $4.85 \mu \mathrm{m}$, respectively, while the width of the second $\mathrm{O}$ noticeably increased to $243 \mathrm{~nm}$ as shown in Fig. 3(c). The fraction of the total $\mathrm{O}$ phase increased from $59.26 \%$ to $78.24 \%$, the size of the primary $\mathrm{O}$ was so large that the volume fraction increased from $19.65 \%$ to $36.30 \%$ as shown in Tab 1 . Slow cooling was good for the growth of second acicular $\mathrm{O}$ phase, the aspect ratio of second acicular $\mathrm{O}$ changed obviously from 5.6 to 2.8 in the

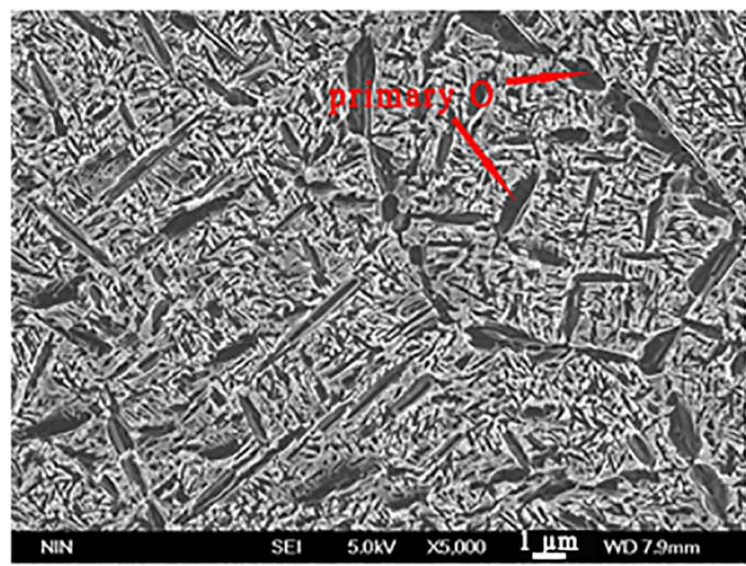

(a) STA $\left(1000^{\circ} \mathrm{C} / 1 \mathrm{~h} / \mathrm{WQ}+820^{\circ} \mathrm{C} / 8 \mathrm{~h} / \mathrm{FC}\right)$

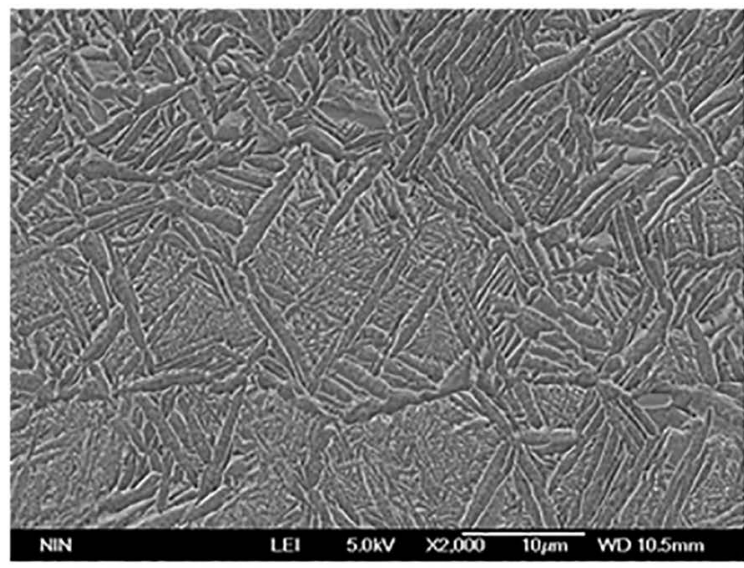

(c) annealed at $1000^{\circ} \mathrm{C} / 1 \mathrm{~h} / \mathrm{FC}$
STA condition to the furnace condition. With slow cooling at $1{ }^{\circ} \mathrm{C} / \mathrm{min}$ until $800{ }^{\circ} \mathrm{C}$, the second $\mathrm{O}$ phase was much coarsened, the $\mathrm{O}$ phase with the width greater than $0.45 \mu \mathrm{m}$ was counted as the primary $\mathrm{O}$, so that all the $\mathrm{O}$ phase in the Fig. 3(d) was observed as all the primary lamellar O. The length and the width of the $\mathrm{O}$ phase was examined as $2.37 \mu \mathrm{m}$ and $1.60 \mu \mathrm{m}$, respectively, and the aspect ratio decreased to 1.48 . The volumes and the microstructural characteristics of $\mathrm{O}$ phase precipitated under different conditions are shown in the table 1.

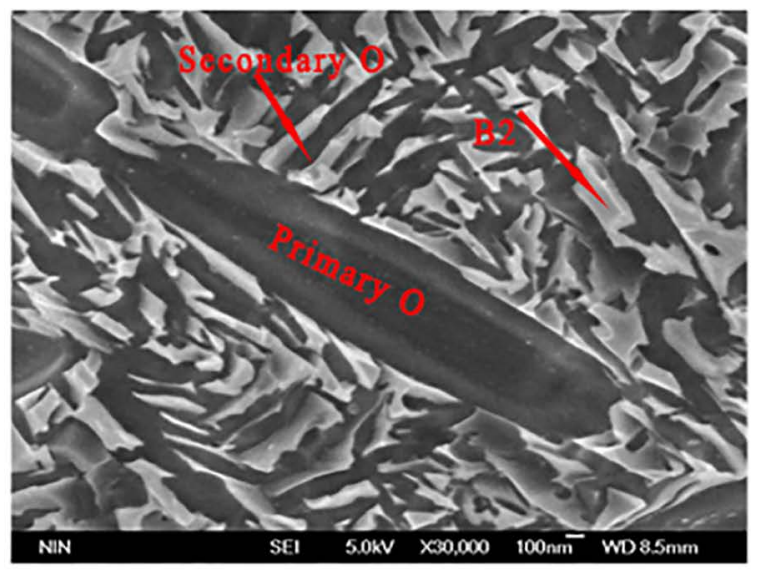

(b) Local magnification of fig. a

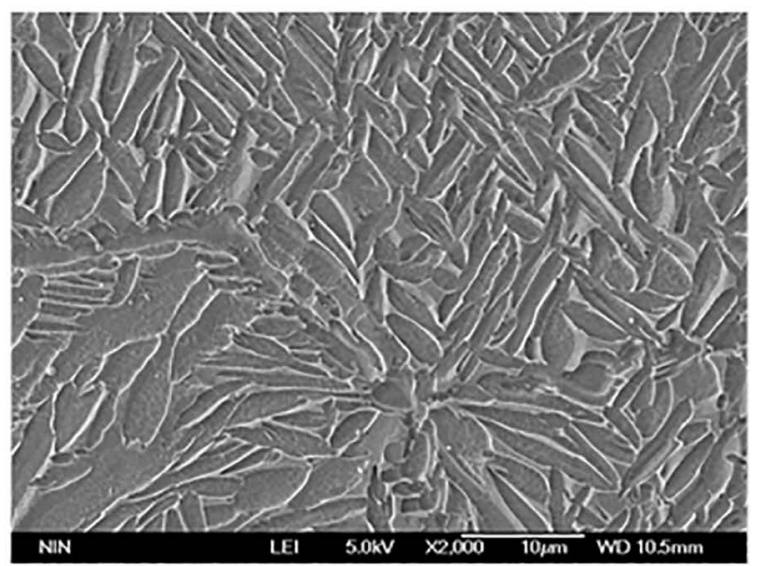

(d) annealed at $1000^{\circ} \mathrm{C}$ and followed by cooling at $1^{\circ} \mathrm{C} / \mathrm{min}$.

Figure 3. As-adjusted microstructures of current wrought $\mathrm{Ti}_{2} \mathrm{AlNb}$ alloy.

Table 1. Microstructure characteristics of O-phase precipitates

\begin{tabular}{ccccccccc}
\hline & & \multicolumn{3}{c}{ Primary O } & \multicolumn{4}{c}{ Secondary O } \\
\cline { 3 - 9 } States & Total O content \% & Content $\%$ & $\begin{array}{c}\text { Mean } \\
\text { length }(\mu \mathrm{m})\end{array}$ & $\begin{array}{c}\text { Mean } \\
\text { width }(\mu \mathrm{m})\end{array}$ & $\begin{array}{c}\text { Aspect } \\
\text { ratio }\end{array}$ & $\begin{array}{c}\text { Mean } \\
\text { length }(\mu \mathrm{m})\end{array}$ & $\begin{array}{c}\text { Mean } \\
\text { width }(\mu \mathrm{m})\end{array}$ & $\begin{array}{c}\text { Aspect } \\
\text { ratio }\end{array}$ \\
\hline STA & 59.26 & 19.65 & 2.58 & 0.67 & 3.85 & 0.42 & 0.075 & 5.6 \\
Annealed with furnace cooling & 78.24 & 36.30 & 4.85 & 0.98 & 4.9 & 0.68 & 0.24 & 2.8 \\
Annealed with a slow cooling & 80.79 & 100 & 2.37 & 1.60 & 1.48 & - & - & - \\
\hline
\end{tabular}




\subsection{Evaluation of mechanical properties}

Fig. 4 lists the room-temperature (RT) and high-temperature $\left(700{ }^{\circ} \mathrm{C}\right)$ tensile properties of the wrought alloy at various heat-treated states. STA at $1000{ }^{\circ} \mathrm{C}$ produced the highest yield strength (YS) of $1100 \mathrm{MPa}$ and the ductility was $8 \%$, while after furnace cooling until $800{ }^{\circ} \mathrm{C}$, the YS values decreased to $970 \mathrm{MPa}$ and elongation went up to $10 \%$. Through slow cooling of $1{ }^{\circ} \mathrm{C} / \mathrm{min}$, the YS values decreased by $10 \mathrm{MPa}$, while the highest elongation at RT went up to $12 \%$. The YS at $700{ }^{\circ} \mathrm{C}$ decreased from $950 \mathrm{MPa}$ to $850 \mathrm{MPa}$ in the STA to the furnace cooling, while the elongation remained almost same in two states. However, for the $1{ }^{\circ} \mathrm{C} / \mathrm{min}$, the YS increased to $860 \mathrm{MPa}$ and recorded the highest ductility of $17 \%$.

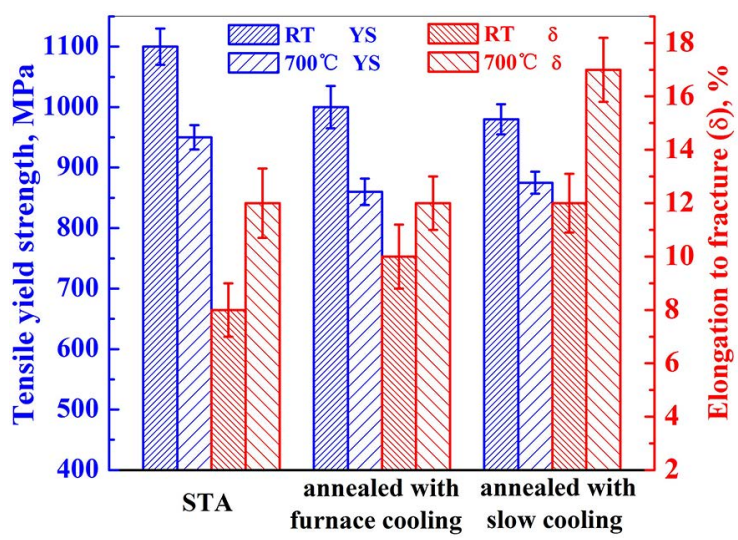

Figure 4. Tensile properties of the present forged $\mathrm{Ti}_{2} \mathrm{AlNb}$ alloy.

To study further the relationship between strength and microstructure, detailed morphologies of both matrix B2 phase and second acicular $\mathrm{O}$ phase were observed by TEM, as shown in Fig. 5((a)-(c)), showing the absence for diffraction plots of $\alpha_{2}$ phase. Decreasing the cooling rate in a slow process, the second acicular $\mathrm{O}$ phase became more and more thicker as shown in table 1. Comparing Fig. 5(a) with 5(b), the density of dislocations in the furnace cooling was low, suggesting that many dislocations around the fine secondary
O phase, which could improve the strength. However, the merging of dislocations and the plugging would cause the crack to nucleate, which could reduce the plasticity. with the cooling rate of $1{ }^{\circ} \mathrm{C} / \mathrm{min}$, dislocations almost disappeared (Fig. 5(c)) between the lamellar O phase, while the black region corresponded to the $\mathrm{B} 2$ matrix with many slip systems facilitating the coordinate deformation and correlating the microstructure with highest ductility ${ }^{25}$.

For $\mathrm{Ti}_{2} \mathrm{AlNb}$ alloys, the following factors influenced the mechanical properties: (1) grain size of B2 matrix; (2) the volume fraction and size of primary orthorhombic $\mathrm{O}$ phases; (3) the aspect ratio of the second O phase; (4) the density of dislocations. Four factors could influence each other in examining tensile properties of the alloy.

(1) The presence of $\beta / B 2$ phase and the size of grain are essential in ameliorating the ductility of this alloy ${ }^{2}$. In the casting process, the rare earth element $\mathrm{Y}$ is added to form $\mathrm{Y}_{2} \mathrm{O}_{3}$, and the grain boundary is pinned, then the cast structure can be refined. During the forging process, large grains are broken into small grains. During the thermal deformation process, sufficient distortion energy is accumulated, and dynamic recrystallization occurs, which further reduces the original B2 grains to about $60 \mu \mathrm{m}$. More grain boundaries can increase the strength and provide the nucleation point for $\mathrm{O}$ phases during heat treatment.

(2) With the increase of volume fraction of the primary O (from $19.65 \%$ to $36.3 \%$ and $100 \%$ ) phase, the plasticity gradually increases, indicating that the primary $\mathrm{O}$ phase is conducive to the improvement of the ductility. In addition, the reduction of the aspect ratio of the $\mathrm{O}$ phase, the generation of crack at $\mathrm{O}$ and O interfaces is inhibited, which is also beneficial to the improvement of elongation, so that in the cooling rate of $1{ }^{\circ} \mathrm{C} / \mathrm{min}$, the elongation gets the highest of $12 \%$.

(3) As the cooling rate decreased, the width of the secondary acicular $\mathrm{O}$ phase increased significantly, the length changed slightly, and the aspect ratio significantly decreased (from 5.6 to 2.8 and 1.48).

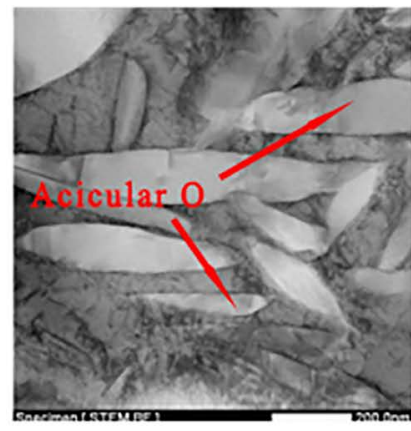

(a) STA treated

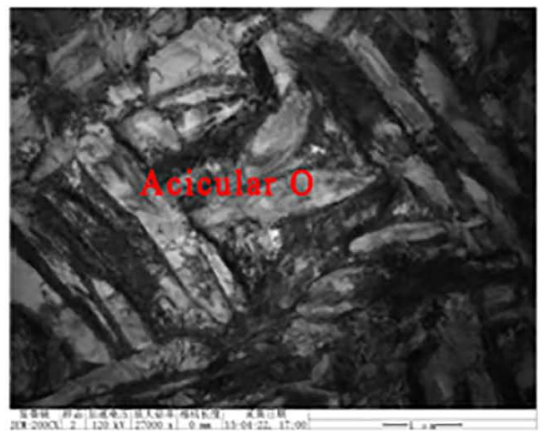

(b) annealed with furnace cooling

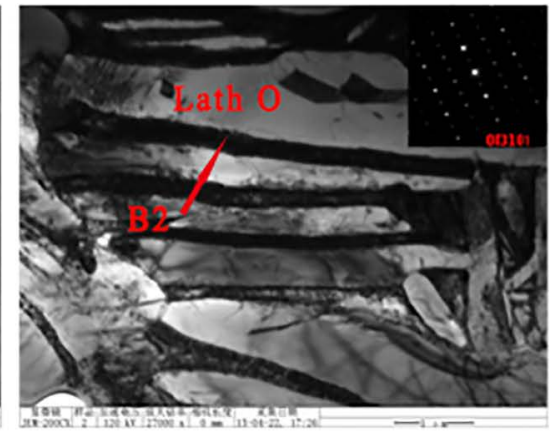

(c) ann ealed with slow cooling

Figure 5. Bright-field TEM images of current forged $\mathrm{Ti}_{2} \mathrm{AlNb}$ alloy. 
the volume of the primary $\mathrm{O}$ is about $19 \%$, massive second fine $\mathrm{O}$ can be good for the tensile the strength, According to the Hall-Petch formula ${ }^{26}$, Slender secondary $\mathrm{O}$ phase contributed to improving the strength, so that in the STA, the strength gets the best of $1100 \mathrm{MPa}$.

(4) The density around the fine acicular $\mathrm{O}$ is high in the STA. Dislocations tangle and plug to increase strength, while that would cause the crack to nucleate and reduce the plasticity. In the cooling rate of $1{ }^{\circ} \mathrm{C} / \mathrm{min}$, dislocations disappear, B2 phases appear between the $\mathrm{O}$ and $\mathrm{O}$ laths and the aspect ratio is the least, so that the elongation at the room and $700{ }^{\circ} \mathrm{C}$ is the highest.

\section{Conclusions}

1. The as-forged $\mathrm{Ti}_{2} \mathrm{AlNb}$ alloy exhibited Widmanstatten structure.

2. In the process of STA, the primary lenticular $\mathrm{O}$ phase precipitated prior at the grain boundaries, and secondary acicular $\mathrm{O}$ phase with width of $0.42 \mu \mathrm{m}$ appears prior in the B2 grain; Annealing at $1000{ }^{\circ} \mathrm{C} / 1 \mathrm{~h} / \mathrm{FC}$, the width of secondary $\mathrm{O}$ phases was $0.68 \mu \mathrm{m}$, By the slow cooling at $1^{\circ} \mathrm{C} / \mathrm{min}$ until $800{ }^{\circ} \mathrm{C}$, the second $\mathrm{O}$ phase grew up to $1.60 \mu \mathrm{m}$.

3. With the cooling rate slowing down, the size got coarsened. the STA microstructure exhibited the highest tensile strength up to $1100 \mathrm{MPa}$ with a slightly low elongation of $8 \%$; Annealing at $1000^{\circ} \mathrm{C}$ improved the tensile ductility and produced an excellent elongation up to $10 \%$. In particular, annealing with a slow cooling process further enhanced the tensile elongation to $12 \%$.

\section{Acknowledgments}

This work was financially supported by the National Key Development Program of the Ministry of Science and Technology of China under Grant No. 2017YFB0305603, the National Natural Science Fundation of China under Grant Nos. 51301140 and 51371064, the Equipment Preresearch Fund of China under Grant No. 61409230409, the Fundamental Research Funds for the Central Universities under Grant No. 02080022117003 and Ningbo Natural Science Foundation under Grant No. 2018A610060.

\section{References}

1. Boehlert CJ. Part III. The tensile behavior of Ti-Al-Nb O+Bcc orthorhombic alloys. Metallurgical and Materials Transactions A. 2001;32(8):1977-1988.

2. Gogia AK, Nandy TK, Banerjee D, Carisey T, Strudel JL, Franchet JM. Microstructure and mechanical properties of orthorhombic alloys in the Ti-Al-Nb system. Intermetallics. 1998;6(7-8):741-748.
3. Xue C, Zeng W, Xu B, Liang X, Zhang J, Li S. B2 grain growth and particle pinning effect of Ti-22Al-25Nb orthorhombic intermetallic alloy during heating process. Intermetallics. 2012;29:41-47.

4. Boehlert CJ. Phase evolution and microstructural stability of an orthorhombic Ti-23Al-27Nb alloy. Journal of Phase Equilibria. 1999;20(2):101-108.

5. Boehlert CJ, Majumdar BS, Seetharaman V, Miracle D. Part I. The microstructural evolution in Ti-AI-Nb O + Bcc orthorhombic alloys. Metallurgical and Materials Transactions A. 1999;30(9):2305-2323.

6. Sun Y, Zeng W, Ma X, Xu B, Liang X, Zhang J. A hybrid approach for processing parameters optimization of Ti-22Al$25 \mathrm{Nb}$ alloy during hot deformation using artificial neural network and genetic algorithm. Intermetallics. 2011;19(7):1014-1019.

7. Boehlert CJ, Bingert JF. Microstructure, tensile, and creep behavior of $\mathrm{O}+\mathrm{BCCTi} 2 \mathrm{AlNb}$ alloys processed using inductionfloat-zone melting. Journal of Materials Processing Technology. 2001;117(3):400-408.

8. Boehlert CJ. The effects of forging and rolling on microstructure in O+BCC Ti-Al-Nb alloys. Materials Science and Engineering: A. 2000;279(1-2):118-129.

9. Wang W, Zeng W, Xue C, Liang X, Zhang J. Designed bimodal size lamellar $\mathrm{O}$ microstructures in Ti2AlNb based alloy: Microstructural evolution, tensile and creep properties. Materials Science and Engineering: A. 2014;618:288-294.

10. Dey SR, Roy S, Suwas S, Fundenberger JJ, Ray RK. Annealing response of the intermetallic alloy Ti-22Al-25Nb. Intermetallics. 2010;18(6):1122-1131.

11. Banerjee D. The intermetallic Ti2AlNb. Progress in Materials Science. 1997;42(1-4):135-158.

12. Tang F, Nakazawa S, Hagiwara M. Creep Behavior of Orthorhombic Ti2AINb Based Intermetallic Alloys. Proceedings of the 7th International Conference on Creep and Fatigue at Elevated Temperatures - CREEP7; 2001 Jun 3-8; Tsukuba, Japan.

13. Cowen CJ, Boehlert CJ. Comparison of the Microstructure, Tensile, and Creep Behavior for Ti-22Al-26Nb (At. Pct) and Ti-22Al-26Nb-5B (At. Pct). Metallurgical and Materials Transactions A. 2007;38(1):26-34.

14. Hagiwara M, Emura S, Araoka A. Property Enhancement of Orthorhombic Ti2AlNb-Based Intermetallic Alloys. Materials Science Forum. 2003;426-432:1715-1720.

15. Hagiwara M, Emura S, Araoka A, Kong BO, Tang F. Enhanced mechanical properties of orthorhombic Ti2AlNb-based intermetallic alloy. Metal and Materials International. 2003;9(3):265-272.

16. F.A. Shen Jun. Research progress in microstructure modulation and thermoforming of Ti2AlNb based alloys. Acta Metallurgica Sinica. 2013;49(11):9.

17. Boehlert CJ, Majumdar BS, Krishnamurthy S, Miracle DB. Role of matrix microstructure on room-temperature tensile properties and fiber-strength utilization of an orthorhombic ti-alloy-based composite. Metallurgical and Materials Transactions A. 1997;28(2):309-323.

18. Wang W, Zeng W, Xue C, Liang X, Zhang J. Microstructure control and mechanical properties from isothermal forging and heat treatment of $\mathrm{Ti}-22 \mathrm{Al}-25 \mathrm{Nb}$ (at.\%) orthorhombic alloy. Intermetallics. 2015;56:79-86. 
19. Yang SJ, Nam SW, Hagiwara M. The Role of W in Orthorhombic Ti2AlNb Based Intermetallic Alloy for the Enhancement of Creep Properties above 700oC. In: Ti-2003: Science and Technology; Proceedings of the 10th World Conference on Titanium; 2003 Jul 13-18; Hamburg, Germany.

20. Cao X, Xu J. Microstructure and Mechanical Properties of (a2+O+B2) Three-Phase T13Al Based Alloy. Titanium Industry Progress. 2008;5:15-19.

21. Chen X, Zeng W, Wang W, Liang X, Zhang J. The enhanced tensile property by introducing bimodal size distribution of lamellar O for O+B2 Ti2AlNb based alloy. Materials Science and Engineering: A. 2013;587:54-60.

22. Zheng Y, Zeng W, Li D, Zhao Q, Liang X, Zhang J, et al. Fracture toughness of the bimodal size lamellar $\mathrm{O}$ phase microstructures in Ti-22Al-25 $\mathrm{Nb}$ (at.\%) orthorhombic alloy. Journal of Alloys and Compounds. 2017;709:511-518.
23. Emura S, Araoka A, Hagiwara M. B2 grain size refinement and its effect on room temperature tensile properties of a Ti-22Al$27 \mathrm{Nb}$ orthorhombic intermetallic alloy. Scripta Materialia. 2003;48(5):629-634.

24. Niu HZ, Chen YF, Zhang DL, Zhang YS, Lu JW, Zhang W, et al. Fabrication of a powder metallurgy Ti2AlNb-based alloy by spark plasma sintering and associated microstructure optimization. Materials \& Design. 2016;89:823-829.

25. Wang W, Zeng W, Li D, Zhu B, Zheng Y, Liang X. Microstructural evolution and tensile behavior of Ti2AlNb alloys based a2phase decomposition. Materials Science and Engineering: A. 2016;662:120-128.

26. Xue C, Zeng W, Wang W, Li X, Zhang J. Coarsening behavior of lamellar orthorhombic phase and its effect on tensile properties for the Ti-22Al-25Nb alloy. Materials Science and Engineering: A. 2014;611:320-325. 